\title{
Investigating the Kinetics of the Thermolysis of 3- nitro-2,4-dihydro-3H-1,2,4-triazol-5-one (NTO) and Reduced Size NTO the Presence of Cobalt Ferrite Additive
}

\author{
pragnesh N Dave ( $\sim$ pragneshdave@gmail.com ) \\ Sardar Patel University \\ Ruksana Sirach \\ Sardar Patel University \\ Riddhi Thakkar \\ Sardar Patel University \\ M P Deshpande \\ Sardar Patel University
}

\section{Research Article}

Keywords: 3-nitro-2,4-dihydro-3H-1,2,4-triazol-5-one (NTO), Cobalt ferrite, Thermal decomposition, High energetic materials, Additive

Posted Date: November 11th, 2021

DOI: https://doi.org/10.21203/rs.3.rs-1062980/v1

License: (c) (1) This work is licensed under a Creative Commons Attribution 4.0 International License.

Read Full License 


\section{Abstract}

Less sensitive high energetic materials (HEMs) are explored as a potential replacement of highly sensitive HEMs in propellants, and explosive applications. More research have been devoted to improve the thermal decomposition of such a less sensitive HEMs. Nanosize Cobalt ferrite (CoF) has been successfully synthesized using the co-precipitation method. Synthesis of less sensitive HEM 3-nitro-2,4dihydro-3H-1,2,4-triazol-5-one(NTO) and its size reduction using solvent-antisolvent method is successfully achieved. Effect of $5 \%$ by weight CoF on the thermolysis of NTO and NTO with reduced size (r-NTO) has been studied using the simultaneous thermal analysis. Three isoconversional methods namely Flynn Ozawa Wall, Kissinger-Akahira-Sunose (KAS), and Starink are employed to evaluate the kinetic parameter of NTO, and r-NTO in the presence of CoF additive. It was found that both the addition of CoF as well as reducing size of NTO can decrease the thermal decomposition temperature of NTO, the later decreasing the thermal decomposition temperature to a good extent compared to former. However, the kinetic study using isoconversional methods suggested that in the presence of CoF additive, the activation energy of both NTO as well as n-NTO is increased.

\section{Introduction}

High energetic materials (HEMs) are extensively utilized in propellants, explosives and pyrotechnics due to extensive heat and gas released during their thermal decomposition. Few of the most widely known HEMs include ammonium perchlorate (AP), cyclotetramethylene tetranitramine (HMX), and cyclotrimethylene trinitramine (RDX). These HEMs are highly sensitive to external stimuli such as shock, and friction, therefore, it is a very challenging task to handle such sensitive HEMs during their handling as small mistake can lead to an accident.[1, 2] More research is being devoted to replace the highly sensitive HEMs with less sensitive HEMs. The preparation of new less sensitive HEMs has certain limitations such as chemical compatibility, poor stability, and decomposition performance[3]. Hence, more research is devoted to improve the performance of the existing less sensitive HEMs. 3-nitro-2,4-dihydro-3H-1,2,4triazol-5-one (NTO)'s highly insensitive, ease of manufacturing, safe handling, and high detonation velocity makes NTO one of the most promising candidate. $[4,5]$ The improvement in the thermal decomposition of NTO is achieved by (i) Use of additives[3, 4, 6], (ii) Reducing size of NTO[7], (iii) Formation of co-crystal with other HEMs[8, 9]. One of the most widely studied additives for HEMs are transition metals and its analogues.[3, 10,11] The transition metal oxides can act as an effective additive due to (i) availability of wide range of oxidation states that can participate during the thermal decomposition process, (ii) availability of large surface, (iii) Activeness to participate in the reactions. The transition metals of $3 \mathrm{~d}$ series specifically $\mathrm{Fe}, \mathrm{Co}, \mathrm{Ni}, \mathrm{Cu}, \mathrm{Zn}$ are known to possess good catalytic activity for reducing the thermal decomposition temperature of HEMs. Transition metal ferrites are the widely employed in the catalytic applications because of their effectiveness, ease of synthesis, utilization of less expensive chemicals, and environmental friendliness as they can be easily separated using a magnet due to their magnetic nature.[12-14] Prabhakaran et al.[4] have reported that the presence of additives can effect (increase or decrease) the decomposition temperature of NTO. 
In this paper as per best of our knowledge we firstly report effect of CoF on NTO, and NTO with reduced size (r-NTO). CoF was synthesized via the co-precipitation route and characterized using XRD, AFM, Raman, UV analysis. NTO was synthesized in lab and reduction in the size of NTO was achieved using solvent-antisolvent method. The effect of $5 \%$ by weight CoF additive on both NTO as well as r-NTO was investigated using simultaneous TG-DSC-DTA. Three isoconversional methods namely Flynn-Wall-Ozawa (FWO), Kissinger-Akahira-Sunose(KAS), and Starink method were used to evaluate the kinetic parameter.

\section{Materials And Methodology}

Semicarbazide hydrochloride $(\mathrm{SC} . \mathrm{HCl})$, Formic acid $(\mathrm{HCOOH})$, Ferric nitrate $\left(\mathrm{Fe}\left(\mathrm{NO}_{3}\right)_{3}\right)$, Cobalt nitrate $\left(\mathrm{Co}\left(\mathrm{NO}_{3}\right)_{2}\right)$, Sodium hydroxide $(\mathrm{NaOH})$, Tetrahydro Furan $(\mathrm{THF})$, n-hexane, ethanol were acquired from Sisco research laboratories. All the chemicals were of the reagent grade and used as received.

\section{Synthesis of NTO}

NTO was synthesized previously reported methods.[15-17] Equal amount of formic acid and SC.HCl were mixed with continuous stirring and refluxed at $102^{\circ} \mathrm{C}$. After the completion of the reaction excess formic acid was removed by distillation and 2,4-dihydro-3H-1,2,5-Triazol-3-one(TO) was obtained $\left(M P=232^{\circ} \mathrm{C}\right)$. Thereafter, TO was added to excess of nitric acid maintaining the temperature below $5^{\circ} \mathrm{C}$. The solution was refluxed in a microwave reactor (Uwave-1000; serial no.: UW162) at $60^{\circ} \mathrm{C}, 200 \mathrm{~W}$ for 15 minutes. The reaction progress was monitored using TLC employing Ethyl acetate:n-Hexane (8:2) as a mobile phase. After the completion of the reaction, solution mixture was poured onto ice, NTO was filtered re-crystallised using ethanol solvent, and dried in an oven overnight at $60^{\circ} \mathrm{C}$. (Yield of NTO=68.5 $\%)$

\section{Reduction in size}

Size of the synthesized NTO was reduced using solvent antisolvent technique.[18] Saturated solution of NTO was prepared in $100 \mathrm{~mL}$ THF solvent and sonicated for half an hour. This saturated solution of NTO was added to the chilled $n$-hexane $\left(<0^{\circ} \mathrm{C}, 400 \mathrm{~mL}\right)$ via a syringe under magnetic stirring to obtain small size NTO precipitates (r-NTO). The obtained precipitates were filtered and dried in an oven overnight at 60 ${ }^{\circ} \mathrm{C}$ (Yield=66.17\%). (Fig. 1)

Fig. 1 Scheme for the synthesis of NTO, and r-NTO

\section{Synthesis of cobalt ferrite}

CoF was synthesized using the co-precipitation method. Equal quantity of salts of $\mathrm{Co}\left(\mathrm{NO}_{3}\right)_{2}(0.2 \mathrm{M}, 150$ $\mathrm{mL})$ and $\mathrm{Fe}\left(\mathrm{NO}_{3}\right)_{3}(0.4 \mathrm{M}, 150 \mathrm{~mL})$ were mixed with continuous stirring. To this mixture $2 \mathrm{M} \mathrm{NaOH}$ solution was added to obtain black precipitation. The precipitation was completed at $\sim 11-12 \mathrm{pH}$ (consumed $2 \mathrm{M} \mathrm{NaOH}=125 \mathrm{~mL}$ ). The obtained precipitates were filtered, washed with warm water, and 
calcined at $500{ }^{\circ} \mathrm{C}$ for 5 hours. The obtained CoF powder was utilized for the characterization and as an additive.

\section{Incorporation of nanoadditive}

For the preparation of NTO+CoF, NTO and CoF were mechanically mixed using mortar pestle in 95:5 weight ratio. Similarly, for r-NTO+CoF, r-NTO and CoF were mixed in 95:5 ratio. The prepared compositions were further used for simultaneous TG-DSC-DTA analysis for the evaluation of the thermal decomposition parameters.

\section{Characterization}

The UV-VIS analysis was carried out using Shimadzu UV-1800 UV/VIS Spectrophotometer. UV-VIS spectrum was recorded between 200 to $800 \mathrm{~nm}$ range in dilute hydrochloric acid solution. Raman analysis was performed by JobinYvon Horiba LabRam, HR800 laser sources with a $532 \mathrm{~nm}$ wavelengths. Powder X-ray diffraction (XRD) patterns were analyzed by a Rigaku Ultima IV Powder X-Ray Diffractometer instrument equipped with a Cu Ka radiation source $\left(\lambda=1.5406 A^{\circ}\right)$. Atomic force microscopy (AFM, NT-MDT, Ntegra Aura) was employed for the topographic morphology of CoF.

\section{Catalytic activity}

The catalytic activity of the synthesized CoF particles on both NTO and r-NTO was investigated using simultaneous TG-DSC-DTA (Perkin Elmer, STA 8000) at three heating rates $\left(5,10\right.$, and $\left.15^{\circ} \mathrm{C} / \mathrm{min}\right)$ from room temperature to $400{ }^{\circ} \mathrm{C}$ temperature under $\mathrm{N}_{2}$ atmosphere in a Platinum pan. The thermal data was further utilized to calculate the activation energy of NTO and r-NTO in the presence of CoF additive.

As per the ICTAC kinetics committee recommendations[19], three heating rates $\left(5,10,15^{\circ} \mathrm{C} / \mathrm{min}\right)$ were used to evaluate thermo kinetic parameters. DSC peak area was used to evaluate extent of conversion (a) at various heating rates using Eq. 1 . Where, $\mathrm{dH} / \mathrm{dt}$ represents heat flow. Further, three isoconversional integral methods FWO (Eq. 2)[20, 21], KAS (Eq. 3)[22, 23], and Starink (Eq. 4)[24] were used to evaluate activation energy $\left(E_{\alpha}\right)$, and pre exponential factor $(A)$ at varying extent of conversion. Where, $\beta, R, T$, and $\mathrm{g}(\mathrm{a})$ represents heating rate $\left(\mathrm{K} / \mathrm{min}\right.$ or $\left.{ }^{\circ} \mathrm{C} / \mathrm{min}\right)$, universal gas constant $(8.314 \mathrm{~J} / \mathrm{K} \cdot \mathrm{mol})$, Temperature $(\mathrm{K})$, and integral reaction model respectively. Among the 41 reaction models $\mathrm{g}(\mathrm{a})$ reported elsewhere[25], the most suitable model for NTO, r-NTO, NTO+CoF, and r-NTO+CoF is represented in Table S1. $E_{a}$ is evaluated from the slope and $\ln A$ from the intercept of the Plots of $\ln \beta, \ln \left(\beta / T^{2}\right)$, and $\ln \left(\beta / T^{1.92}\right)$ against $1000 / T$ $\left(K^{-}\right)$. 
$\alpha=\frac{\int_{0}^{t}\left(\frac{d H}{d t}\right) d t}{\int_{0}^{t}\left(\frac{d H}{d t}\right) d t}=\frac{\Delta H}{\Delta H_{\text {total }}}$

$\ln \beta=\ln \left(\frac{0.0048 A E_{a}}{g(\alpha) R}\right)-1.0516 \frac{E_{a}}{R T}$

$\ln \left(\frac{\beta}{T^{2}}\right)=\ln \left(\frac{A R}{g(\alpha) E_{a}}\right)-\frac{E_{a}}{R T}$

$\ln \left(\frac{\beta}{T^{1.92}}\right)=\ln \left(\frac{A R^{0.92}}{E_{a}^{0.92}}\right)-0.312-1.0008 \frac{E_{a}}{R T}$

\section{Results And Discussions}

XRD patterns of CoF, and r-NTO are depicted in Fig. 2. The XRD patterns of CoF appears at peak positions at $18.36^{\circ}, 30.27^{\circ}, 35.60^{\circ}, 43.7^{\circ}, 53.22^{\circ}, 54.06^{\circ}$, and $62.65^{\circ}$ at planes (111), (220), (311), (400), (422), (511), and (440) respectively.[26] The peaks of r-NTO appears at $18.01^{\circ}, 19.50^{\circ}, 20.84^{\circ}, 24.86^{\circ}, 27.24^{\circ}$, $28.44^{\circ}, 31.41^{\circ}, 32.90^{\circ}, 35.14^{\circ}, 36.45^{\circ}, 38.41^{\circ}, 40.94^{\circ}, 42.43^{\circ}, 44.97^{\circ}, 47.80^{\circ}, 51.50^{\circ}, 53.75^{\circ}, 55.98^{\circ}$, $60.60^{\circ}, 65.67^{\circ}$. The XRD pattern was confirmed the formation of r-NTO.[27] The Scherrer formula was used to calculate the crystalline size of $\mathrm{CoF}$, and NTO from maximum peak intensity (i.e., $\mathrm{CoF}=35.60^{\circ}$; $r$ NTO $=27.24^{\circ}$ ) of the XRD pattern.

$$
D=\frac{0.9 \lambda}{\beta \cos \theta}
$$

Where, $\lambda$ represents wavelength, $\beta$ represents full width half maxima (FWHM) of the peak, $\theta$ represents the peak position, and $D$ is the calculated crystalline size $(\mathrm{nm})$. The calculated size of CoF was $22.14 \mathrm{~nm}$, and that of r-NTO was $38.39 \mathrm{~nm}$. Both the calculated sized confirms the nanoscale size. Further the AFM image (Fig. 3) of CoF confirms the formation of nanosize of CoF particles. As depicted in the image CoF particles exhibits wide range of particle size distribution. Majority of the particles exist in the range of 69 to $92 \mathrm{~nm}$.

The UV-VIS spectrum of CoF, NTO, r-NTO, NTO+CoF, and r-NTO+CoF is given in Fig. 4. All the samples exhibit characteristic absorbance in the wavelength region of 200 to $400 \mathrm{~nm}$. The absorbance in the 
wavelength region 250 to $400 \mathrm{~nm}$ confirms the nitration of TO into NTO as TO doe not show absorbance is presence in this region (Fig. S1). r-NTO absorbs in the lower wavelength range compared to NTO, this depicts that r-NTO is smaller in size compared to NTO. According to the previous studies,[28, 29], same material with large size shows higher absorbance at wide wavelength range. In the presence of CoF additive, the absorbance of NTO, and r-NTO is increased compare to that without CoF additive as CoF also absorbs in this wavelength region. The Tauc's plot (Fig. 4-Inset) was used to calculate the band gap energy of CoF using Eq. 6. Where, hv is the photon energy (eV), $E_{g}$ is the band gap energy, $a$ is the absorption coefficient, and $\mathrm{B}$ is constant. The calculated band gap energy of CoF from tauc's plot is 3.19 $\mathrm{eV}$, which is larger than the reported value[30] of $2.89 \mathrm{eV}$. It is reported[31] that the optical band gap energy increases with increasing size. Increased optical band gap energy could be due to the larger size of $\mathrm{CoF}$.

$$
(\alpha h v)^{2}=B\left(h v-E_{g}\right)
$$

The Raman spectrum of CoF, NTO, r-NTO are given in Fig. 5. CoF gives five Raman active modes in the region of 200 to $800 \mathrm{~cm}^{-}$. The peaks at Raman shift 206, 314, 394, 479, and 687 corresponds to $T_{2 g}, E_{g}$,

$T_{2 g}, T_{2 g}$, and $A_{1 g}$ respectively and corresponds to vibrational modes at octahedral and tetrahedral sites. $[30,32]$ The presence of these peaks confirms the formation of spinel CoF. The Raman spectrum confirms the formation of NTO as the peaks matches with that of the reported values.[33] The details regarding the peak position of NTO can be found in Table S2. Upon reducing the size of NTO, (i) the corresponding Raman peaks of NTO are broadened, (ii) Shifting of Raman peak position to higher wavenumbers, and (iii) increased Raman intensity of the peaks (Fig. 6). It is reported[34] that particles with smaller size (e.g., nanosize) broadens the peak compared to corresponding bulk material. The broadening in the Raman peak confirms that reduction in the size of NTO has been successfully achieved. The same is confirmed by measuring the bulk density of NTO, and r-NTO. The bulk density of NTO, and r-NTO powder was 0.51 and $0.29 \mathrm{~g} / \mathrm{mL}$ respectively. The reduced bulk density of r-NTO powder depicts that the synthesized r-NTO is indeed smaller in size compared to NTO as same quantity of r-NTO acquires more volume compared to NTO. The shifting in the Raman peaks in case of r-NTO to a higher Raman shift also confirms that r-NTO is smaller in size compare to NTO. As Raman shift is size dependent, and as particle size is increased peaks shifts to lower Raman shift values[35-37]. Further, the Raman peak intensity of NTO is higher compare to NTO.

\section{Thermal Decomposition}

TG and DTG curves of NTO, r-NTO in the presence as well as absent of CoF are depicted in Fig. 7. Thermal decomposition of NTO starts at onset temperature $\left(\mathrm{T}_{0}\right) 257.45^{\circ} \mathrm{C}$, with a maximum peak temperature $\left(T_{m}\right) 259.45^{\circ} \mathrm{C}$, and ends at $\left(T_{e}\right) 263.45^{\circ} \mathrm{C}$. The total decomposition occurs between only 6 ${ }^{\circ} \mathrm{C}$ range (corresponding time $=36 \mathrm{~s}$ ) with a weight loss of $78.18 \%$ leaving polymeric residue after 
decomposition.[38] In the presence of $5 \%$ CoF additive, the decomposition of NTO occurs at a higher temperature between the temperature range 258.28 to $264.28^{\circ} \mathrm{C}$ with a $\mathrm{T}_{\mathrm{m}}$ of $261.28^{\circ} \mathrm{C}$. The decomposition time remains same (i.e., $36 \mathrm{~s}$ ) with a total weight loss of $75.40 \%$. The weight loss in case of NTO+CoF is $2.78 \%$ less as compared pure NTO. Decomposition of r-NTO in the presence of additive is shifted from 254.32 to $258.32{ }^{\circ} \mathrm{C}(24 \mathrm{~s})$ to $252.25-256.25$ (24 s) ${ }^{\circ} \mathrm{C}$. The DTG peak temperature is also lowered 256.32 to $254.32^{\circ} \mathrm{C}$. The weight loss in case of r-NTO is $77.50 \%$, which is higher $(1.06 \%)$ than in the presence of CoF additive $(76.44 \%)$. The weight loss indicated that product produced during decomposition of NTO, and r-NTO may interact with CoF and yield different weight loss value. The \% weight loss of $\mathrm{CoF}$ is $3.87 \%$ (up to $400^{\circ} \mathrm{C}$, Fig. S2). $5 \% \mathrm{CoF}$ is added to NTO, and r-NTO this means that $0.1935 \%$ weight loss in r-NTO+CoF, and NTO+CoF could be accounted to CoF. The TG-DTG results indicated that the decomposition time of NTO and r-NTO are not affected in the presence of CoF additive, however the decomposition temperature varies in the presence of CoF. TG-DTG curves suggested that although CoF does not exhibit same effect on NTO, and r-NTO. CoF increases the decomposition temperature of NTO but decreases the decomposition temperature of r-NTO. This could be due to the fact that in r-NTO more surfaces may be available for the interaction between CoF and r-NTO compared to micron size NTO. Further, r-NTO decomposes within short time (i.e., 24 s) than NTO (36 s) at lower temperature value $\left(\Delta \mathrm{T}_{\mathrm{m}}=3.13^{\circ} \mathrm{C} ; \mathrm{DTG}\right)$. Although the thermal decomposition mechanism of NTO is not yet clear, the most accepted initial step is hemolytic $\mathrm{C}^{-\mathrm{NO}_{2}}$ bond cleavage followed by ring opening.[1]

DSC and DTA curves $\left(10^{\circ} \mathrm{C} / \mathrm{min}\right)$ of NTO, NTO+COF, r-NTO, and r-NTO+CoF are depicted in the Fig. 8. The effect of various heating rates on DSC curve is given in Fig. 9 and the corresponding DSC data is reported in Table 1. The DSC, and DTA curves are similar. In NTO, no endothermic melting peak is obtained before the decomposition indicating decomposition of NTO occurs before melting.[38] This fact is in contrast with earlier reports information[7]. The single exothermic peak confirms that the decomposition of NTO occurs in a single step. The peak temperature $\left(T_{m}\right)$ along with onset $\left(T_{o}\right)$ and ending temperature $\left(T_{e}\right)$ of NTO decomposition are decreased in case of r-NTO, and NTO+CoF. This indicate that both incorporation of CoF as well as reduction in size of NTO are affective for decreasing the decomposition temperature of NTO. The $T_{m}$ of NTO is decreased by 4.71 and $14.97{ }^{\circ} \mathrm{C}$ using additive and reduction size approach respectively. The total time required for the decomposition is also reduced by $30.78 \mathrm{~s}$ for NTO+CoF, and $39.6 \mathrm{~s}$ for n-NTO compare to NTO. The DSC-DTA results indicated that reducing size of NTO is a better approach for reducing thermal decomposition temperature of NTO than the use of CoF additive. Further, CoF reduces the onset and ending temperature of r-NTO, but the decomposition time along with $\mathrm{T}_{\mathrm{m}}$ of DSC peak is increased by $20.58 \mathrm{~s}$, and $0.75^{\circ} \mathrm{C}$ respectively. The affect of heating rate shows that, DSC curves are shifted to higher temperature values as the heating rate is increased (Fig. 9). This could be because of the fact that because at lower heating rate, sample is heated slowly and spend longer time in the contact with the sample pans leading to decomposition at lower temperature compare to higher heating rates. 
Table 1

DSC curve data for exothermic thermal decomposition of NTO, and r-NTO with and without CoF additives at various heating rates

\begin{tabular}{|c|c|c|c|c|c|c|}
\hline \multirow[t]{2}{*}{ Sample } & \multirow{2}{*}{$\begin{array}{l}\text { Heating rate } \\
\left({ }^{\circ} \mathrm{C} / \mathrm{min}\right)\end{array}$} & \multicolumn{4}{|c|}{ Exothermic peak temperature $\left({ }^{\circ} \mathrm{C}\right)$} & \multirow{2}{*}{$\begin{array}{l}\text { Heat of } \\
\text { decomposition }(\mathrm{J} / \mathrm{g})\end{array}$} \\
\hline & & $\begin{array}{l}\text { Onset } \\
\left(T_{0}\right)\end{array}$ & $\begin{array}{l}\text { Maximum } \\
\left(T_{m}\right)\end{array}$ & $\begin{array}{l}\text { Ending } \\
\left(\mathrm{T}_{\mathrm{e}}\right)\end{array}$ & $\begin{array}{l}\text { TGA \% } \\
\text { loss }\end{array}$ & \\
\hline \multirow[t]{3}{*}{ NTO } & 5 & 261.02 & 266.27 & 267.37 & 80.99 & 176.05 \\
\hline & 10 & 254.65 & 276.35 & 277.60 & 78.18 & 748.24 \\
\hline & 15 & 259.14 & 275.20 & 281.59 & 79.48 & 667.04 \\
\hline \multirow[t]{3}{*}{ NTO+CoF } & 5 & 256.33 & 267.26 & 268.28 & 77.76 & 206.15 \\
\hline & 10 & 255.58 & 271.64 & 273.40 & 75.40 & 370.72 \\
\hline & 15 & 260.51 & 269.92 & 283.05 & 71.32 & 326.55 \\
\hline \multirow[t]{3}{*}{ r-NTO } & 5 & 246.94 & 261.42 & 262.47 & 79.20 & 277.22 \\
\hline & 10 & 253.60 & 261.38 & 269.95 & 77.50 & 197.00 \\
\hline & 15 & 251.93 & 264.28 & 277.16 & 78.08 & 360.58 \\
\hline \multirow{3}{*}{$\stackrel{\mathrm{r}-}{\mathrm{NTO}}+\mathrm{CoF}$} & 5 & 251.39 & 258.30 & 261.40 & 71.91 & 111.89 \\
\hline & 10 & 248.60 & 262.13 & 268.38 & 76.44 & 283.16 \\
\hline & 15 & 249.30 & 264.01 & 274.91 & 73.45 & 376.25 \\
\hline
\end{tabular}

Heat released during the decomposition process is another important factor for deciding HEMs efficiency.

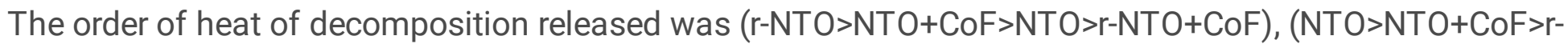
NTO+CoF>r-NTO), and (NTO $>$ r-NTO+CoF $>$ r-NTO $>$ NTO+CoF) at heating rate 5,10 , and $15{ }^{\circ} \mathrm{C}$, respectively. No certain trend was observed in case of heat of decomposition. Therefore, judging the value at only single heating rate will not be accurate. The effect of heating rate on the peak temperature $\left({ }^{\circ} \mathrm{C}\right)$, and heat of decomposition $(\mathrm{J} / \mathrm{g})$ is presented in Fig. 10 for the better understanding. As represented in Fig. 10 (a) that in the presence of CoF, DSC peak temperature is reduced as compare to pure NTO, and r-NTO at two heating rate value. Further, DSC peak temperature of r-NTO is less compare to NTO at all heating rates, indicating reliable results. In case of heat of decomposition (Fig. 10 (b)), it was evident that although CoF, and reducing size of NTO is efficient ways to reduce the decomposition temperature of NTO, the decreased heat of decomposition is a downside of using CoF as an additive and reducing size of NTO. To overcome the drawback of heat released during the decomposition process, CoF can be added to NTO, as r-NTO+CoF decompose at lower temperature with slightly increased heat of decomposition compare to rNTO. To further evaluate the effect of the additive and r-NTO, kinetics parameters such as activation energy and the pre-exponential factors were evaluated at three heating rates. 


\section{Kinetic Study}

The conversion plots (extent of conversion vs. temperature) of NTO, NTO+CoF, r-NTO, r-NTO+CoF at 5, 10, and $15{ }^{\circ} \mathrm{C} / \mathrm{min}$ are presented in Fig. 11. At lower heating rate, the decomposition process begins and ends at lower temperature than at higher heating rates. The trend is same for all samples, i.e., for high heating rates, the conversion process is completed at higher temperature values and vice versa. Further, from the conversion plots, it was evident that in the presence of CoF additive, the conversion begins is completed at within short temperature range as compared to pure NTO, or r-NTO. The temperature at various extent of conversion at an interval of 0.025 was evaluated at three heating rates for calculation of activation energy $\left(E_{a}\right)$ and the pre exponential factor (A). The plots of three methods (FWO, KAS, and Starink) for NTO, NTO+CoF, r-NTO and r-NTO+CoF are presented in Fig. S4 and Fig. S5, in supplementary file. The average value of the $E_{a}$, and $I n A$ are reported in Table 2. The variation in the $E_{a}$, and In $A$ with extent of conversion ( $a$ ) is depicted in Fig. 12. As visible, trend pattern of the changes in the $E_{a}$ and $\ln A$ with respect to $a$ is not altered in the presence of CoF additive (i.e., NTO, and NTO+CoF exhibits similar patterns as well as r-NTO and r-NTO+CoF also exhibit similar pattern). Further, the pattern in case of NTO, and r-NTO are different. The possible cause for this could be due to change in the mechanism pathways. Presence of CoF increases the activation energy along with the pre exponential factor for the decomposition of both NTO, and r-NTO (Fig. 12). Further, the value of $E_{a}$ and In A was lower in case of rNTO compare to NTO up to half way through the reaction, $(a=0.5)$, After that the value of $E_{a}$ and $\ln A$ drops drastically. From the activation energy calculations it was clear that the decomposition of NTO requires high activation energy barrier to surpass $(\sim 369.30 \mathrm{~kJ} / \mathrm{mol})$ which matches with the reported value of (322 to $368 \mathrm{~kJ} / \mathrm{mol})$ [39], efforts are devoted to decrease this large activation energy barrier.[3] 
Table 2

Thermo Kinetics parameters calculated using FWO, KAS, and Starink method along with time of decomposition for NTO, r-NTO, NTO+CoF, and r-NTO+CoF

\begin{tabular}{|llllll|}
\hline Kinetic parameters & $\begin{array}{l}\text { Isoconvesrional } \\
\text { method }\end{array}$ & Composition & & \\
\hline & & NTO & NTO+CoF & r-NTO & $\begin{array}{l}\text { r- } \\
\text { NTO+CoF }\end{array}$ \\
\hline$E_{\mathrm{a}}(\mathrm{kJ} / \mathrm{mol})$ & FWO & 369.30 & 513.75 & 449.39 & 542.51 \\
\hline & KAS & 231.37 & 531.47 & 471.08 & 561.87 \\
\hline Ln A & Starink & 379.55 & 531.41 & 463.86 & 561.7706 \\
\hline & FWO & 89.93 & 123.50 & 110.01 & 131.27 \\
\hline & KAS & 44.53 & 111.80 & 97.83 & 119.64 \\
\hline $\begin{array}{l}\text { Time of decomposition } \\
(\mathrm{s})\end{array}$ & Starink & 70.86 & 104.46 & 90.72 & 112.26 \\
\hline
\end{tabular}

\section{Conclusions}

Two approaches (i) addition of CoF additive, and (ii) reduction in size of NTO are studied in the present research for improving the thermal decomposition of NTO. Reduction in the size of NTO is successfully achieved using solvent-antisolvent approach (crystalline size of r-NTO=38.39 nm). The CoF synthesized using the co-precipitation method show wide particle size distribution with an average crystalline size of $22.14 \mathrm{~nm}$. The following points can be drawn from the thermal decomposition study of NTO:

- Both reducing size of NTO to r-NTO, and use of $5 \%$ CoF additive (NTO+CoF) can improve the exothermic peak temperature of NTO by $14.97^{\circ} \mathrm{C}$, and $4.71^{\circ} \mathrm{C}$.

- The decomposition of NTO begins and ends at lower temperature when NTO+CoF, and r-NTO are used.

- The decomposition time of NTO is not affected in the presence of CoF, but it is reduced by $12 \mathrm{~s}$ when r-NTO is used.

- Heat released during the decomposition process is decreased upon use of NTO+CoF, and r-NTO compare to pure NTO.

- The activation energy as well as pre-exponential factor of decomposition of NTO are decreased when NTO+CoF, and r-NTO are employed.

- Addition of $5 \%$ CoF to r-NTO (r-NTO+CoF) is able to increase the heat of decomposition of r-NTO but it increases the activation energy and pre exponential factor of r-NTO. 


\section{Declarations}

\section{Funding Source}

The present work was funded by the Department of Science and Technology (DST), New Delhi, India (SR/NM/NT-1014/2016 (G)).

\section{Acknowledgements}

Authors RS and RT are thankful to DST (SR/NM/NT-1014/2016 (G)) for providing Junior Research and Research Associate Fellowships, respectively. The authors are grateful to the Department of Chemistry for the research facility, Department of Physics, Sardar Patel University, India, for providing XRD and Raman Facility, and DST purse programme-Indukaka Ipcowala Center for Interdisciplinary Studies in Science and Technology (IICISST)for Simultaneous thermal analysis.

\section{Statement of Conflict of interest:}

The authors declare that they have no conflict of interest.

\section{References}

[1] Sirach RR, Dave PN (2021) 3-Nitro-1,2,4-triazol-5-one (NT0): High Explosive Insensitive Energetic Material. Chem Heterocycl Comp 57:720-730 . https://doi.org/10.1007/s10593-021-02973-9

[2] Hanafi S, Trache D, Abdous S, Bensalem Z, Mezroua A (2019) 5-Nitro-1,2,4-triazole-3-one: A review of recent advances $\mathbb{\bigotimes}$. Chinese J Energ Mater 27:326-347 . https://doi.org/vishwa

[3] Hanafi S, Trache D, He W, Xie W-X, Mezroua A, Yan Q-L (2020) Catalytic effect of 2D-layered energetic hybrid crystals on the thermal decomposition of 3-nitro-2,4-dihydro-3H-1,2,4-triazol-5-one (NTO). Thermochim Acta 692:178747 . https://doi.org/10.1016/j.tca.2020.178747

[4] Prabhakaran KV, Naidu SR, Kurian EM (1994) XRD, spectroscopic and thermal analysis studies on 3nitro-1,2,4-triazole-5-one (NTO). Thermochim Acta 241:199-212 . https://doi.org/10.1016/00406031(94)87018-7

[5] Zhang M, Li C, Gao H, Fu W, Li Y, Tang L, Zhou Z (2016) Promising hydrazinium 3-Nitro-1,2,4-triazol-5one and its analogs. J Mater Sci 51:10849-10862 . https://doi.org/10.1007/s10853-016-0296-7

[6] Kumar D, Kapoor IPS, Singh G, Siril PF, Tripathi AM (2011) Preparation, Characterization, and Catalytic Activity of Nanosized NiO and ZnO: Part 74. Propellants, Explos, Pyrotech 36:268-272 . https://doi.org/10.1002/prep.201000013

[7] Yang G, Nie F, Li J, Guo Q, Qiao Z (2007) Preparation and Characterization of Nano-NTO Explosive. J Energ Mater 25:35-47 . https://doi.org/10.1080/07370650601107104 
[8] Li JC, Jiao QJ, Gong YG, Wang YY, Liang T, Sun J (2018) Explosive performance of HMX/NTO cocrystal. IOP Conf Ser: Mater Sci Eng 292:012032 . https://doi.org/10.1088/1757-899X/292/1/012032

[9] Guo C, Zhang H, Wang X, Liu X, Sun J (2013) Study on a novel energetic cocrystal of TNT/TNB. J Mater Sci 48:1351-1357 . https://doi.org/10.1007/s10853-012-6881-5

[10] Elbasuney S, El-Sayyad GS (2020) The potentials of $\mathrm{TiO}_{2}$ nanocatalyst on HMX thermolysis. J Mater Sci: Mater Electron 31:14930-14940 . https://doi.org/10.1007/s10854-020-04054-7

[11] Elbasuney S, Hamed A, Yehia M, Gobara M, Mokhtar M (2021) The significant impact colloidal nanothermite particles $\left(\mathrm{Fe}_{2} \mathrm{O}_{3} / \mathrm{Al}\right)$ on $\mathrm{HMX}$ kinetic decomposition. J Energ Mater. https://doi.org/10.1080/07370652.2021.1905107

[12] Amiri M, Eskandari K, Salavati-Niasari M (2019) Magnetically retrievable ferrite nanoparticles in the catalysis application. Adv Colloid Interface Sci 271:101982 . https://doi.org/10.1016/j.cis.2019.07.003

[13] Chaturvedi S, Dave PN (2013) A review on the use of nanometals as catalysts for the thermal decomposition of ammonium perchlorate. J Saudi Chem Soc 17:135-149 .

https://doi.org/10.1016/j.jscs.2011.05.009

[14] Chaturvedi S, Dave PN, Shah NK (2012) Applications of nano-catalyst in new era. J Saudi Chem Soc 16:307-325 . https://doi.org/10.1016/j.jscs.2011.01.015

[15] Mukundan T, Pur GN, Nair JK, Pansare SM, Sinha RK, Singh H (2002) Explosive Nitrotriazolone Formulates. Def Sci J 52:127-133

[16] Saikia A, Sivabalan R, Gore GM, Sikder AK (2012) Microwave-Assisted Quick Synthesis of Some Potential High Explosives. Propellants, Explos, Pyrotech 37:540-543.

https://doi.org/10.1002/prep.201100107

[17] Sirach RR, Dave PN (2021) Synthesis of 5-Nitro-1,2,4-Triazol-3-One Via: Conventional Heating, Microwave and Ultrasonication. J Chem Edu Res Prac 5: 42-46

[18] Lee K, Asay BW, Kennedy JE (2013) Method for forming energetic nanopowders, US8557066B1

[19] Vyazovkin S, Burnham AK, Criado JM, Pérez-Maqueda LA, Popescu C, Sbirrazzuoli N (2011) ICTAC Kinetics Committee recommendations for performing kinetic computations on thermal analysis data. Thermochim Acta 520:1-19 . https://doi.org/10.1016/j.tca.2011.03.034

[20] Flynn JH, Wall LA (1966) A quick, direct method for the determination of activation energy from thermogravimetric data. Journal of Polymer Science Part B: Polymer Letters 4:323-328

[21] Ozawa T (1965) A new method of analyzing thermogravimetric data. Bull chem soc Jpn 38:18811886 
[22] Kissinger HE (1956) Variation of peak temperature with heating rate in differential thermal analysis. Journal of research of the National Bureau of Standards 57:217-221

[23] Akahira T, Sunose T (1971) Method of determining activation deterioration constant of electrical insulating materials. Res Rep Chiba Inst Technol (Sci Technol) 16:22-31

[24] Starink MJ (2003) The determination of activation energy from linear heating rate experiments: a comparison of the accuracy of isoconversion methods. Thermochim Acta 404:163-176 . https://doi.org/10.1016/S0040-6031(03)00144-8

[25] Trache D, Abdelaziz A, Siouani B (2017) A simple and linear isoconversional method to determine the pre-exponential factors and the mathematical reaction mechanism functions. J Therm Anal Calorim 128:335-348 . https://doi.org/10.1007/s10973-016-5962-0

[26] Jesus Mercy S, Parajuli D, Murali N, Ramakrishna A, Ramakrishna Y, Veeraiah V, Samatha K (2020) Microstructural, thermal, electrical and magnetic analysis of $\mathrm{Mg}^{2+}$ substituted Cobalt ferrite. Appl Phys A 126:873 . https://doi.org/10.1007/s00339-020-04048-6

[27] Wu J-T, Zhang J-G, Li T, Li Z-M, Zhang T-L (2015) A novel cocrystal explosive NTO/TZTN with good comprehensive properties. RSC Adv 5:28354-28359 . https://doi.org/10.1039/C5RA01124H

[28] Ríos-Corripio MA, García-Pérez BE, Jaramillo-Flores ME, Gayou VL, Rojas-López M (2013) UV-Visible intensity ratio (aggregates/single particles) as a measure to obtain stability of gold nanoparticles conjugated with protein A. J Nanopart Res 15:1624 . https://doi.org/10.1007/s11051-013-1624-3

[29] Kato H, Nakamura A, Takahashi K, Kinugasa S (2009) Size effect on UV-Vis absorption properties of colloidal C60 particles in water. Phys Chem Chem Phys 11:4946-4948 .

https://doi.org/10.1039/B904593G

[30] Swathi S, Yuvakkumar R, Kumar PS, Ravi G, Velauthapillai D (2021) Annealing temperature effect on cobalt ferrite nanoparticles for photocatalytic degradation. Chemosphere 281:130903 . https://doi.org/10.1016/j.chemosphere.2021.130903

[31] Li D, Song H, Meng X, Shen T, Sun J, Han W, Wang X (2020) Effects of Particle Size on the Structure and Photocatalytic Performance by Alkali-Treated TiO2. Nanomaterials 10:546 . https://doi.org/10.3390/nano10030546

[32] Mariosi FR, Venturini J, da Cas Viegas A, Bergmann CP (2020) Lanthanum-doped spinel cobalt ferrite (CoFe204) nanoparticles for environmental applications. Ceram Int 46:2772-2779 . https://doi.org/10.1016/j.ceramint.2019.09.266

[33] Hiyoshi RI, Kohno Y, Nakamura J (2004) Vibrational Assignment of Energetic Material 5-Nitro-2,4dihydro-1,2,4-triazole-3-one (NT0) with Labeled Isomers. J Phys Chem A 108:5915-5920 . 
[34] Nazim M, Khan AAP, Asiri AM, Kim JH (2021) Exploring Rapid Photocatalytic Degradation of Organic Pollutants with Porous CuO Nanosheets: Synthesis, Dye Removal, and Kinetic Studies at Room Temperature. ACS Omega 6:2601-2612 . https://doi.org/10.1021/acsomega.0c04747

[35] Kibasomba PM, Dhlamini S, Maaza M, Liu C-P, Rashad MM, Rayan DA, Mwakikunga BW (2018) Strain and grain size of TiO2 nanoparticles from TEM, Raman spectroscopy and XRD: The revisiting of the Williamson-Hall plot method. Results Phys 9:628-635 . https://doi.org/10.1016/j.rinp.2018.03.008

[36] Swamy V, Muddle BC, Dai Q (2006) Size-dependent modifications of the Raman spectrum of rutile TiO2. Appl Phys Lett 89:163118 . https://doi.org/10.1063/1.2364123

[37] Lin Y, Zhang Y-J, Yang W-M, Dong J-C, Fan F-R, Zhao Y, Zhang H, Bodappa N, Tian X-D, Yang Z-L, Stucky GD, Tian Z-Q, Li J-F (2019) Size and dimension dependent surface-enhanced Raman scattering properties of well-defined Ag nanocubes. Applied Materials Today 14:224-232 .

https://doi.org/10.1016/j.apmt.2018.12.012

[38] Rothgery EF, Audette DE, Wedlich RC, Csejka DA (1991) The study of the thermal decomposition of 3nitro-1,2,4-triazol-5-one (NTO) by DSC, TGA-MS, and ARC. Thermochim Acta 185:235-243 .

https://doi.org/10.1016/0040-6031(91)80045-K

[39] Sinditskii VP, Smirnov SP, Egorshev VYu (2007) Thermal Decomposition of NTO: An Explanation of the High Activation Energy. Propellants, Explos, Pyrotech 32:277-287 .

https://doi.org/10.1002/prep.200700029

\section{Figures}

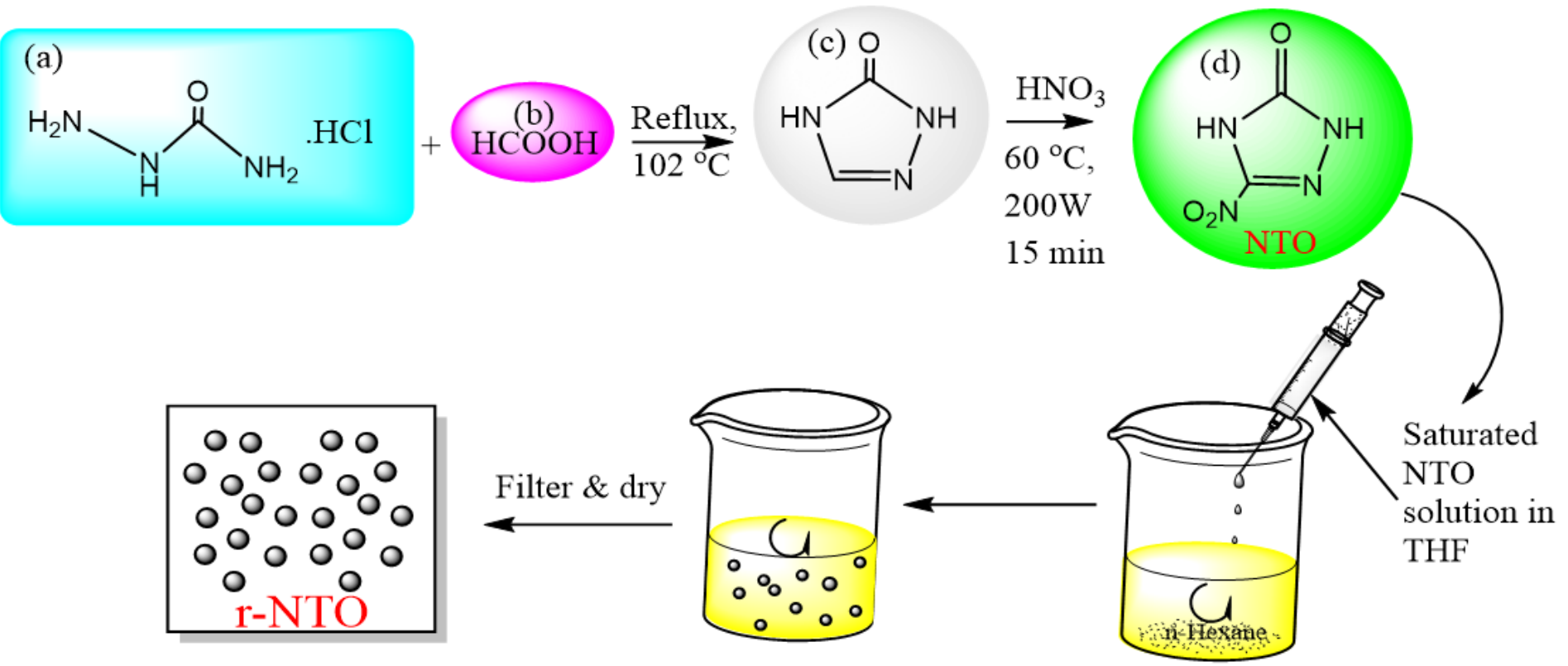


Figure 1

Scheme for the synthesis of NTO, and r-NTO
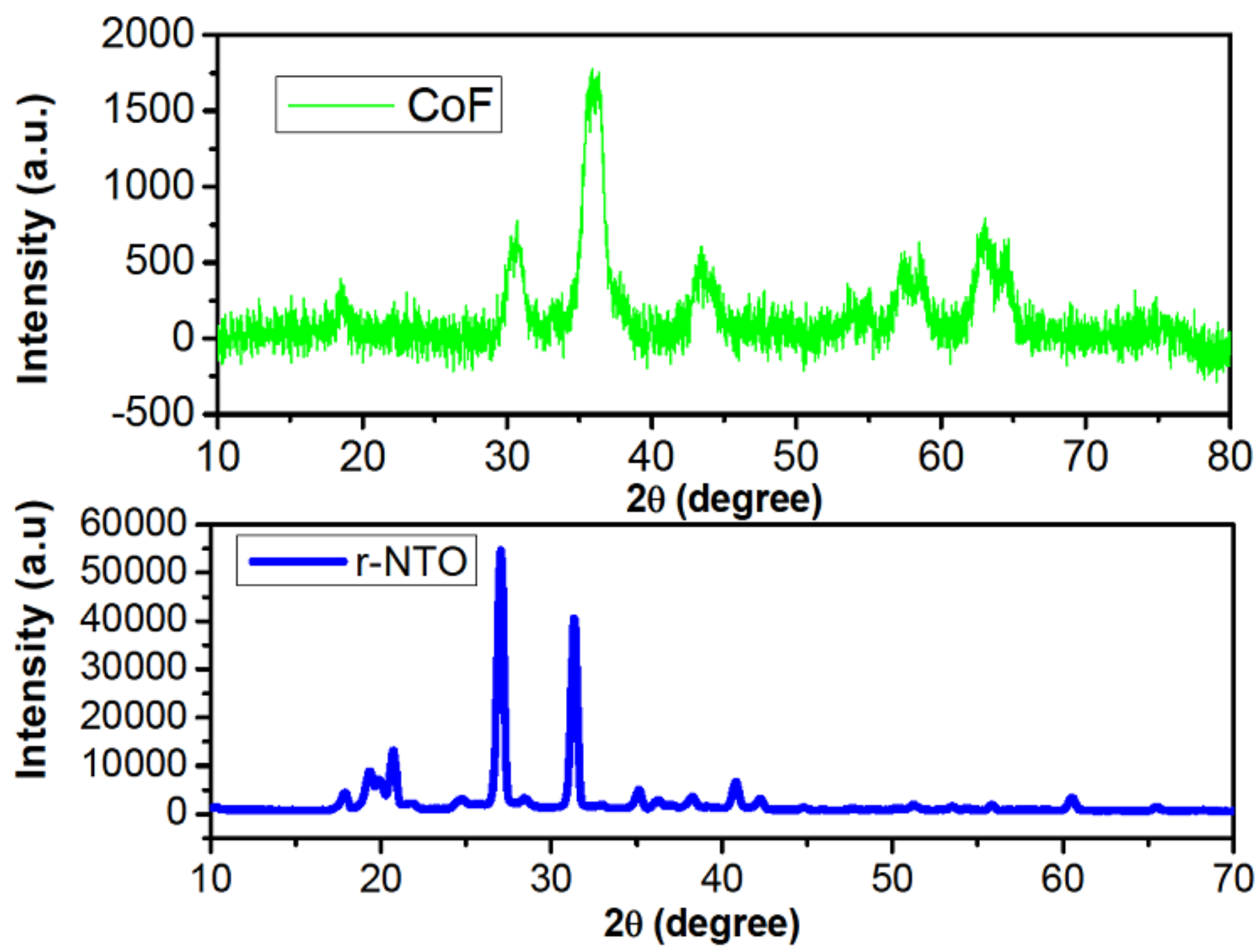

Figure 2

XRD patterns of CoF, and r-NTO 


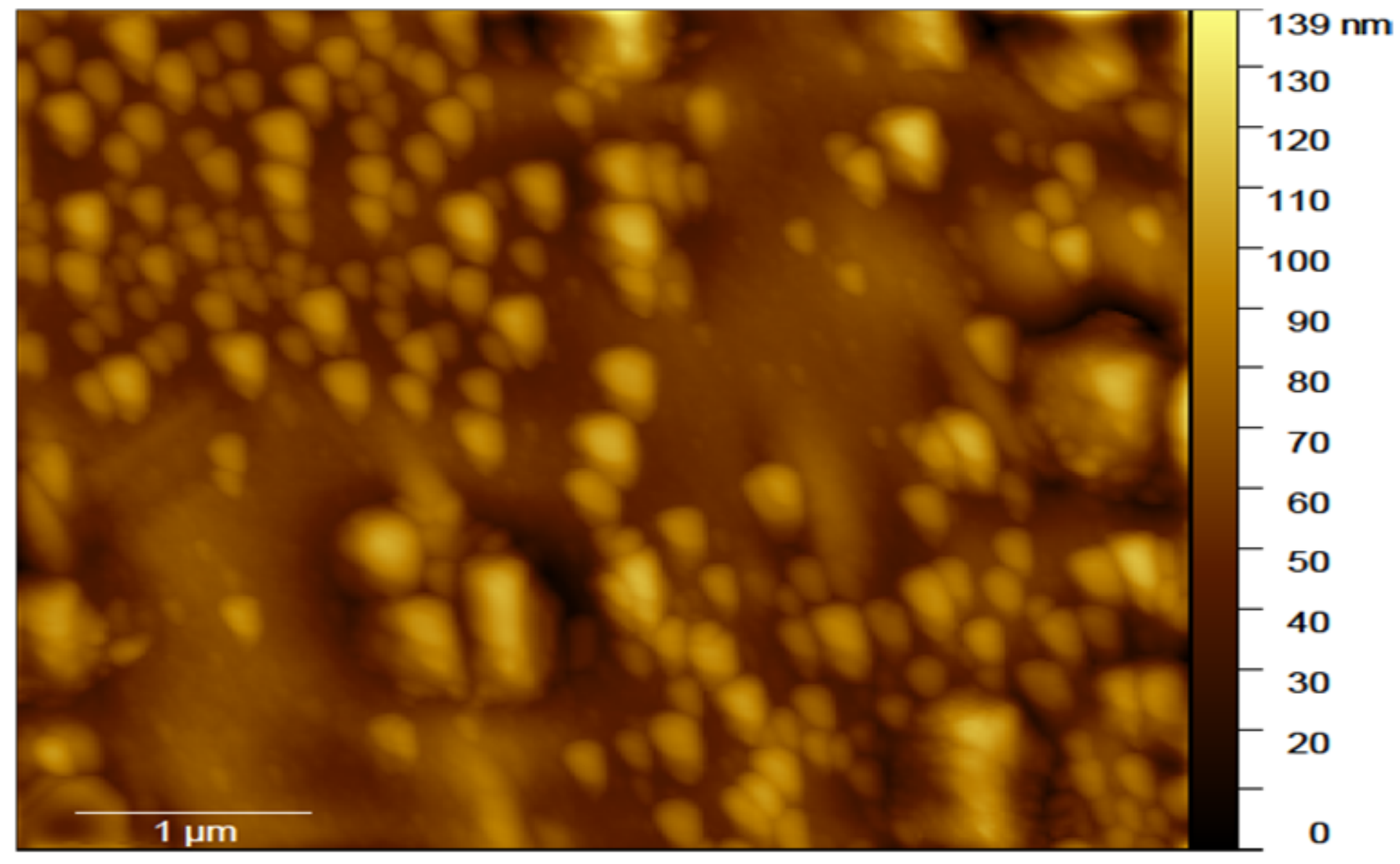

Figure 3

AFM image of CoF 


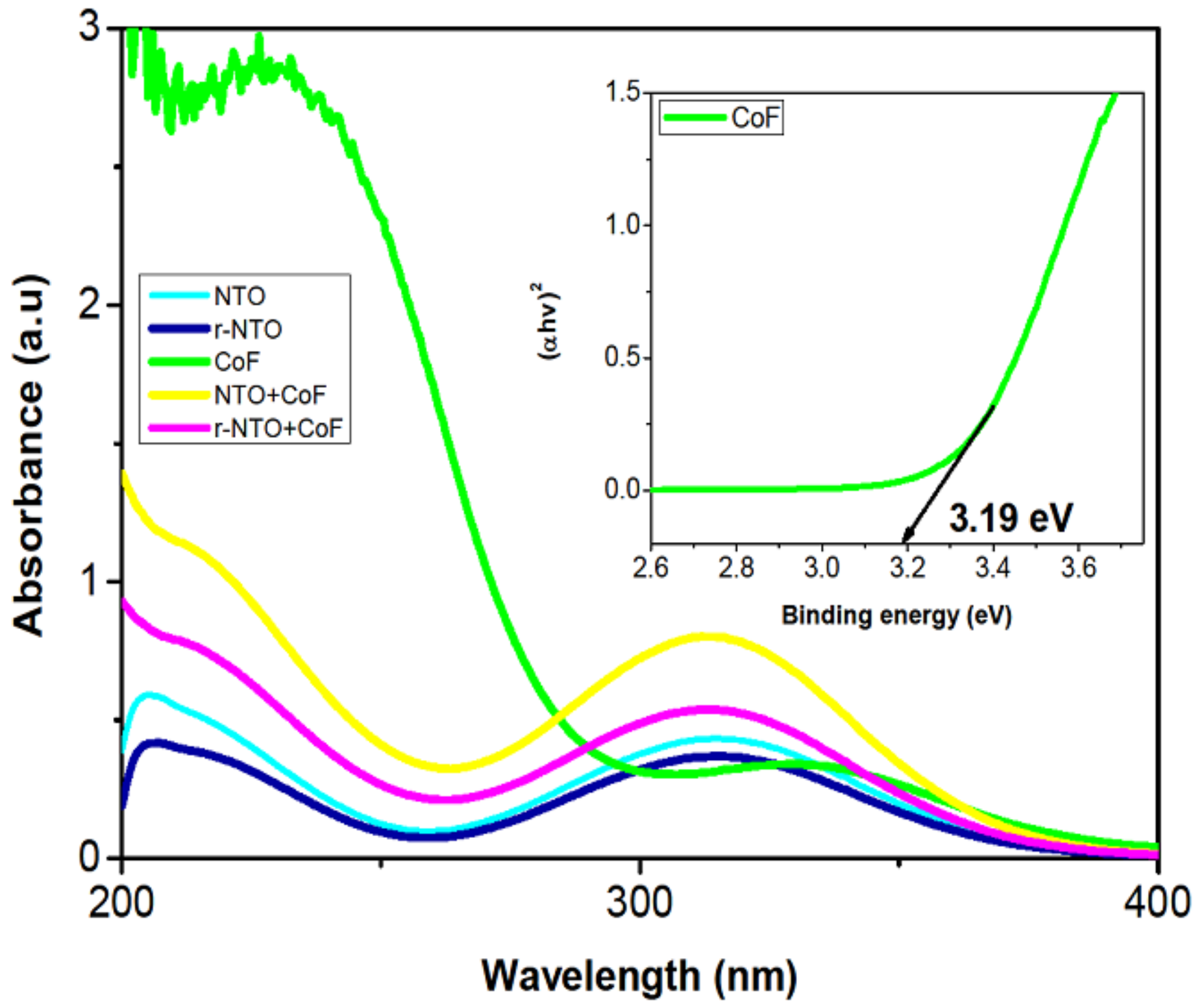

Figure 4

UV-VIS spectrum of NTO, r-NTO, CoF, NTO+CoF, and r-NTO+CoF, (Inset Tauc's plot of CoF) 


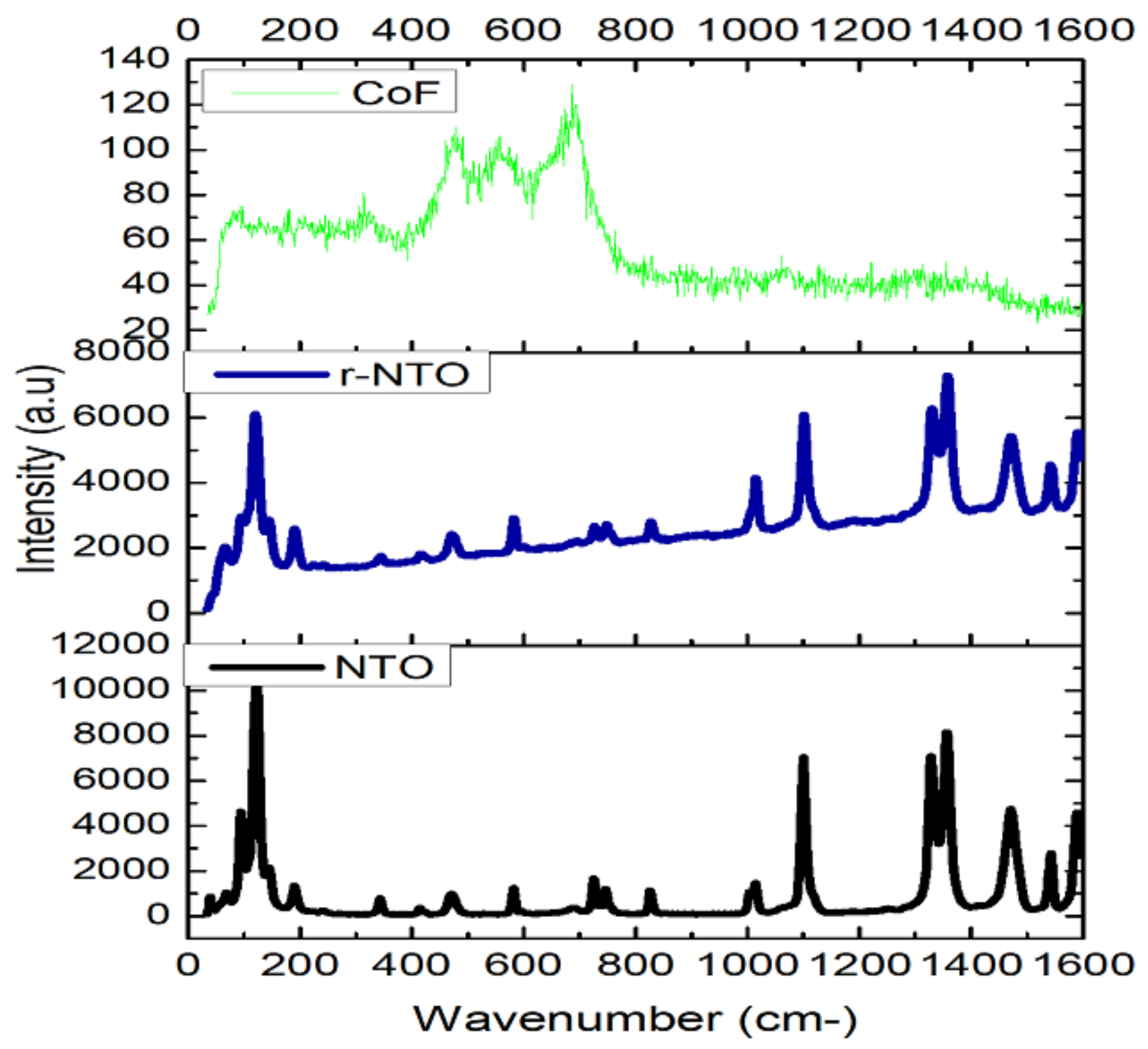

Figure 5

Raman spectrum of CoF, r-NTO, and NTO 

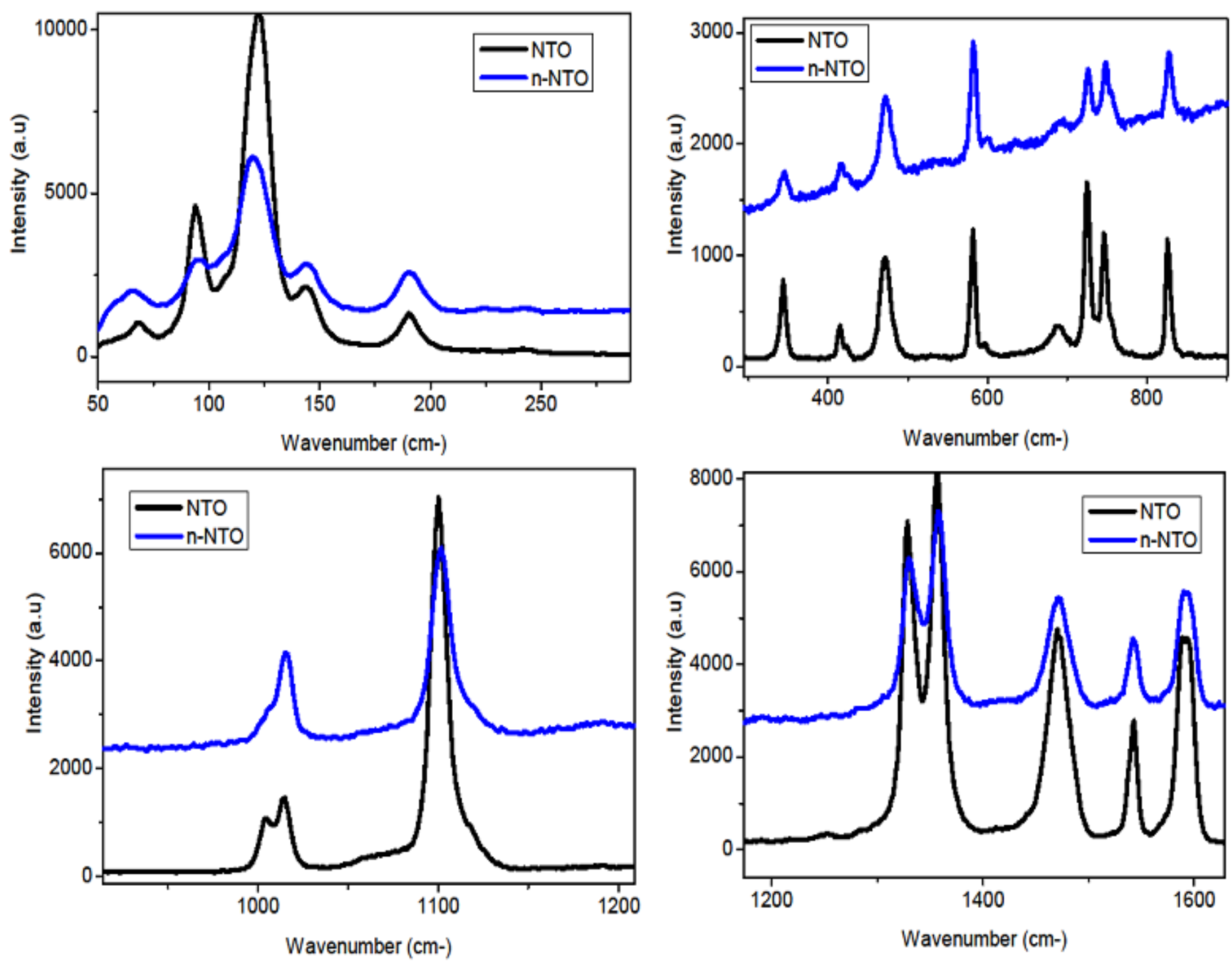

Figure 6

Enlarged view of Raman peaks of NTO, and r-NTO 

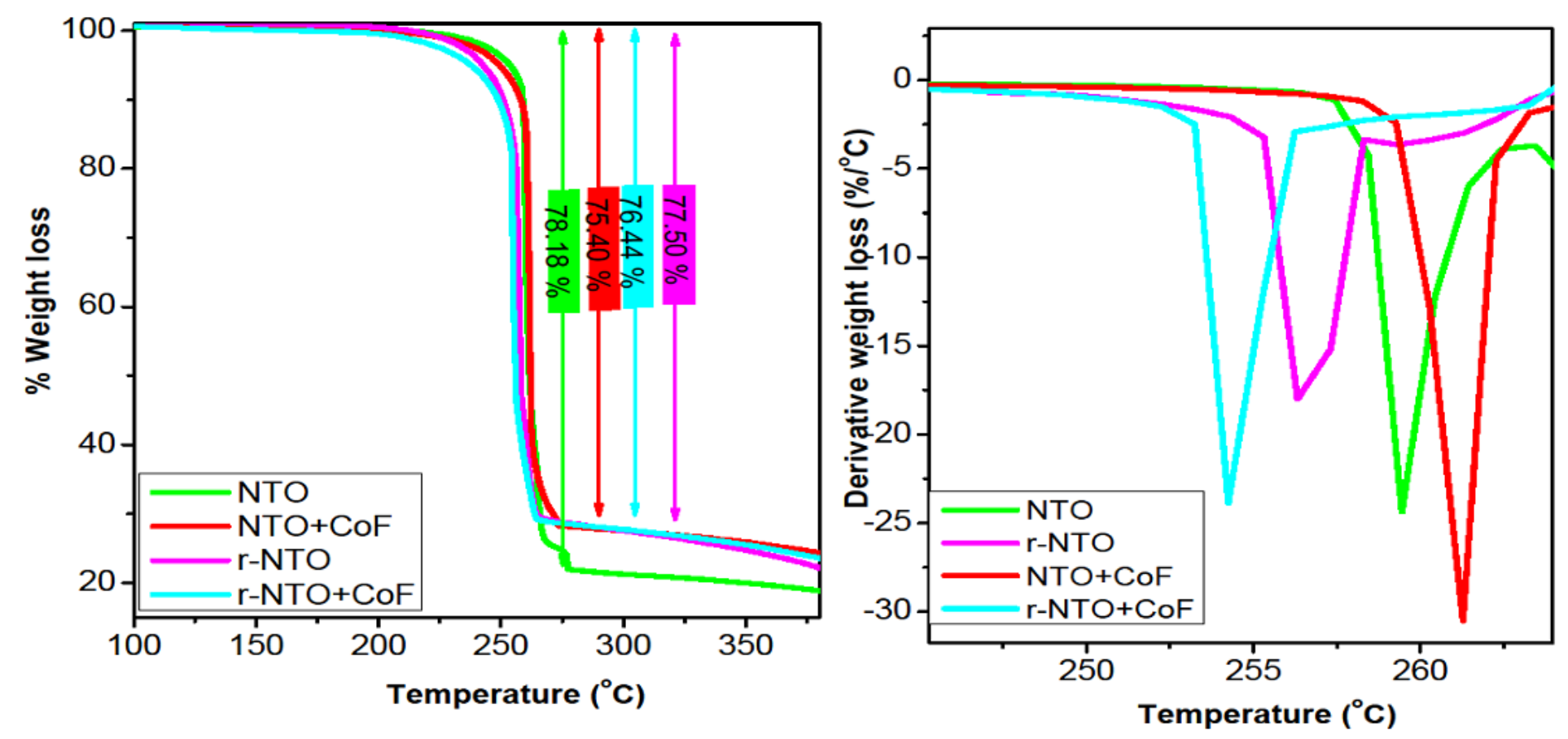

Figure 7

TG and DTG curves of NTO, and r-NTO in the presence of $5 \%$ CoF additive
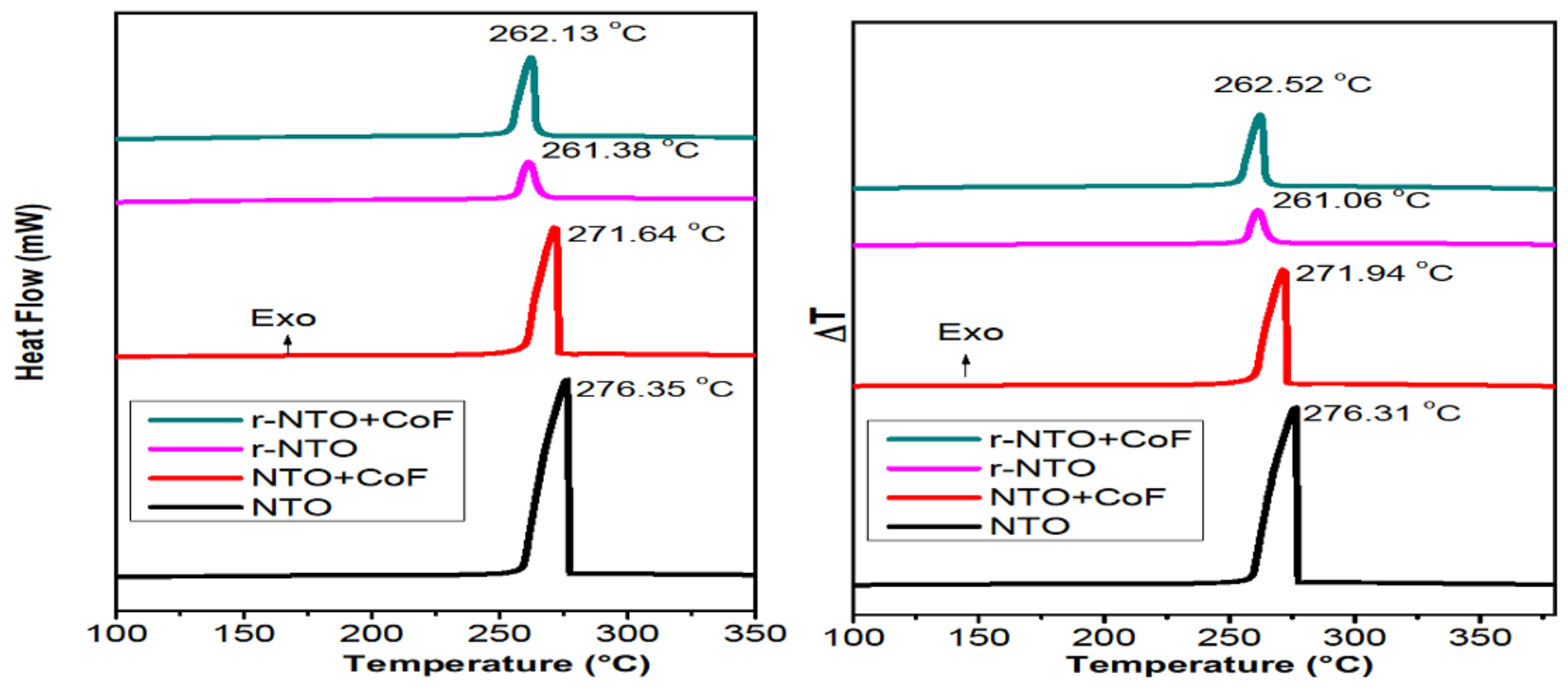

Figure 8

DTA and DSC curves of NTO, and r-NTO in the presence of $5 \%$ CoF additive 

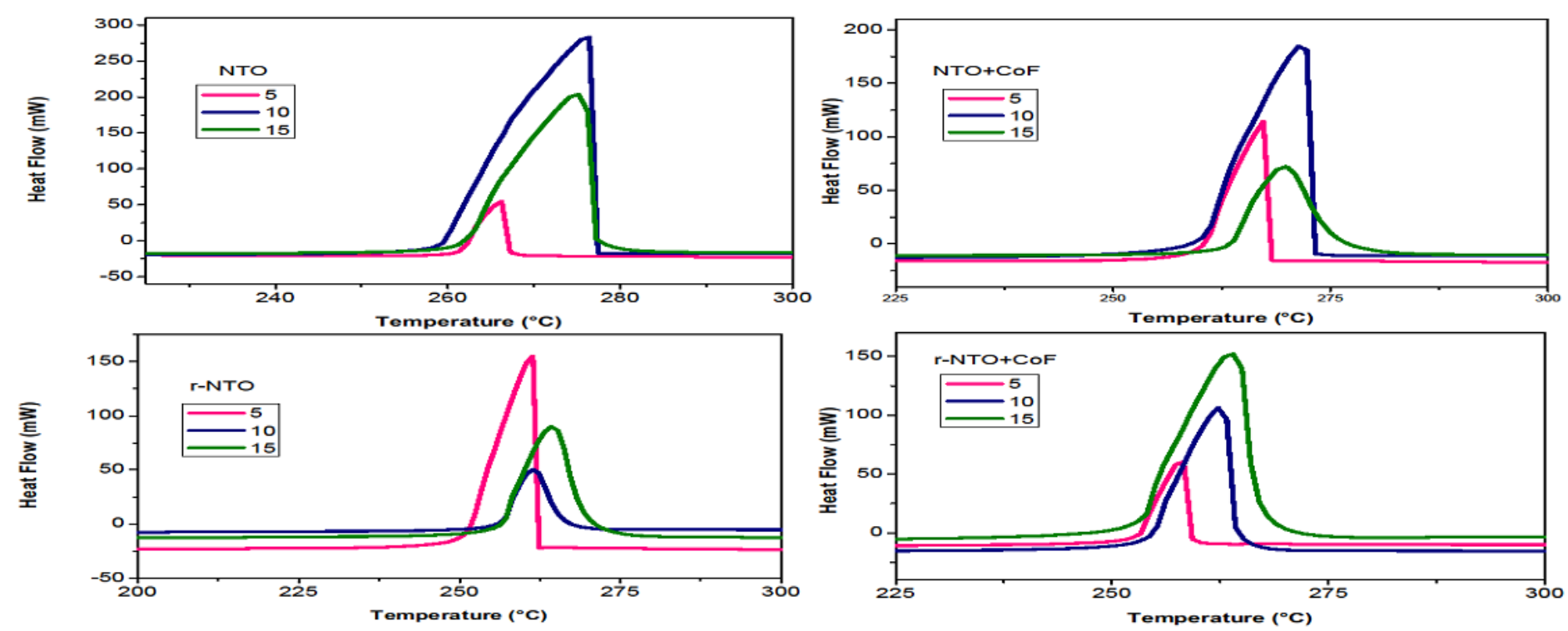

Figure 9

Effect of heating rate on the DSC curves of NTO, r-NTO, NTO+CoF, and r-NTO+CoF
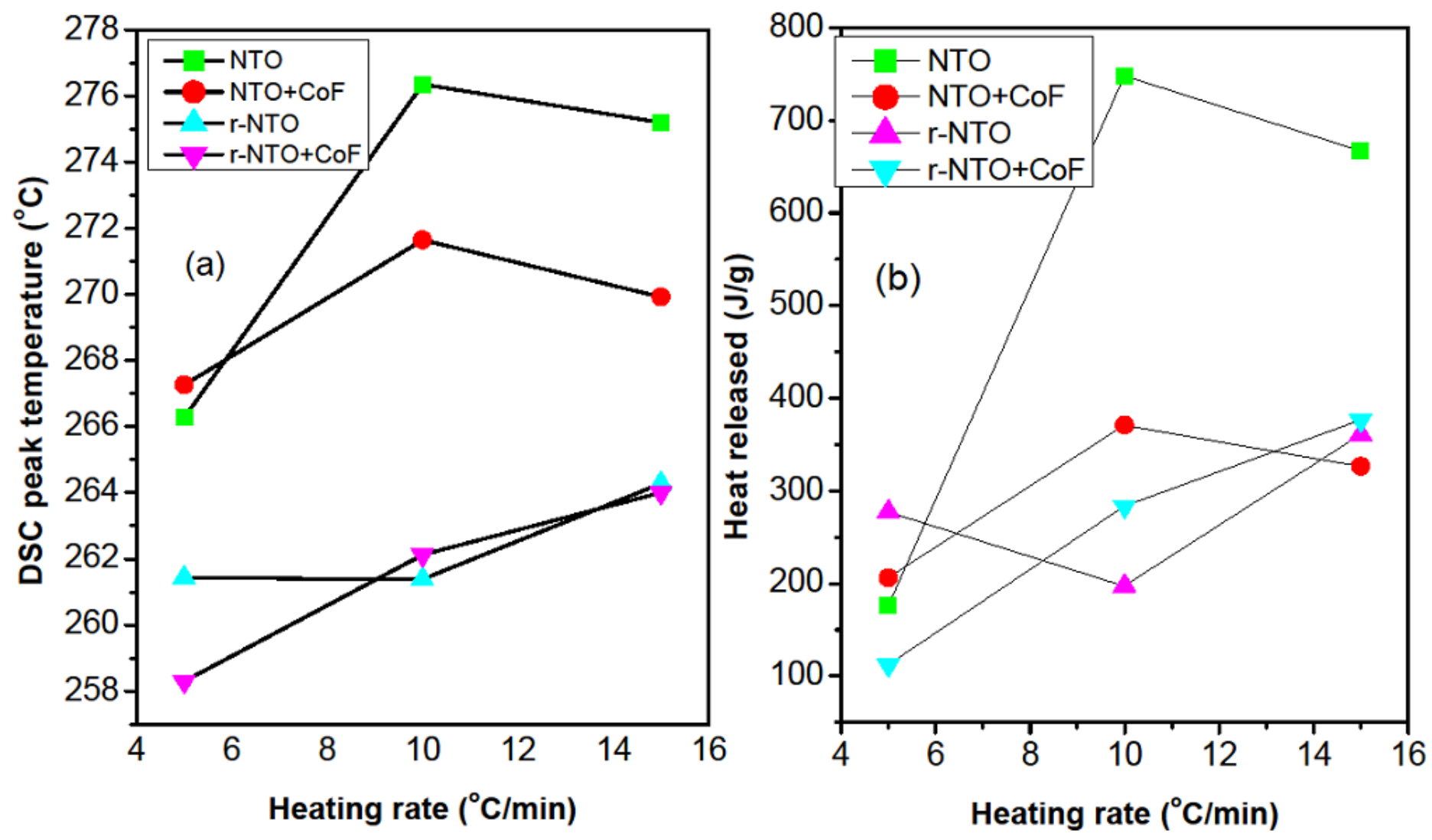

Figure 10

Effect of heating rates on DSC peak temperature (a) and heat of decomposition (b) 

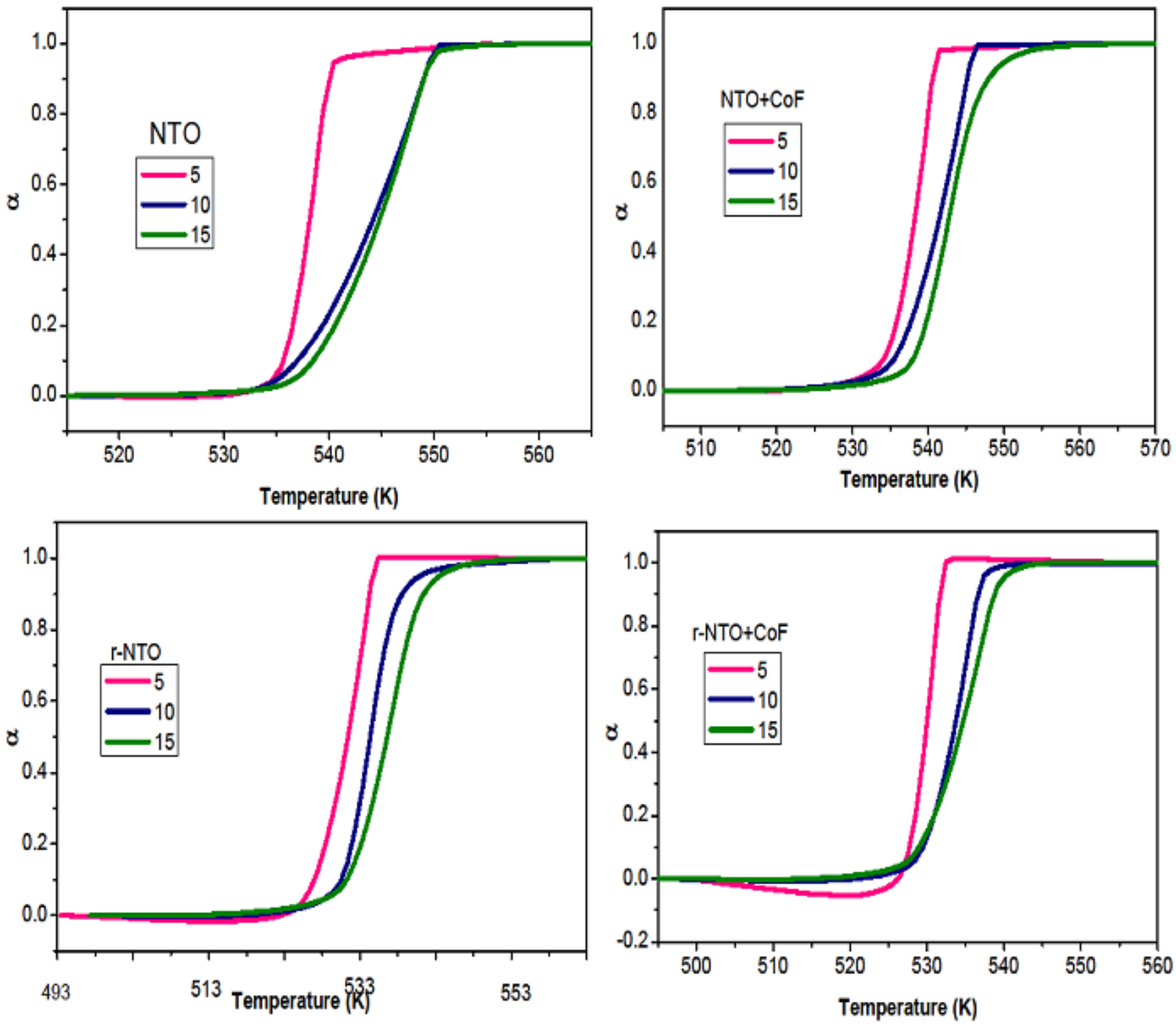

Figure 11

Conversion plots of NTO, and r-NTO with and without CoF additive 

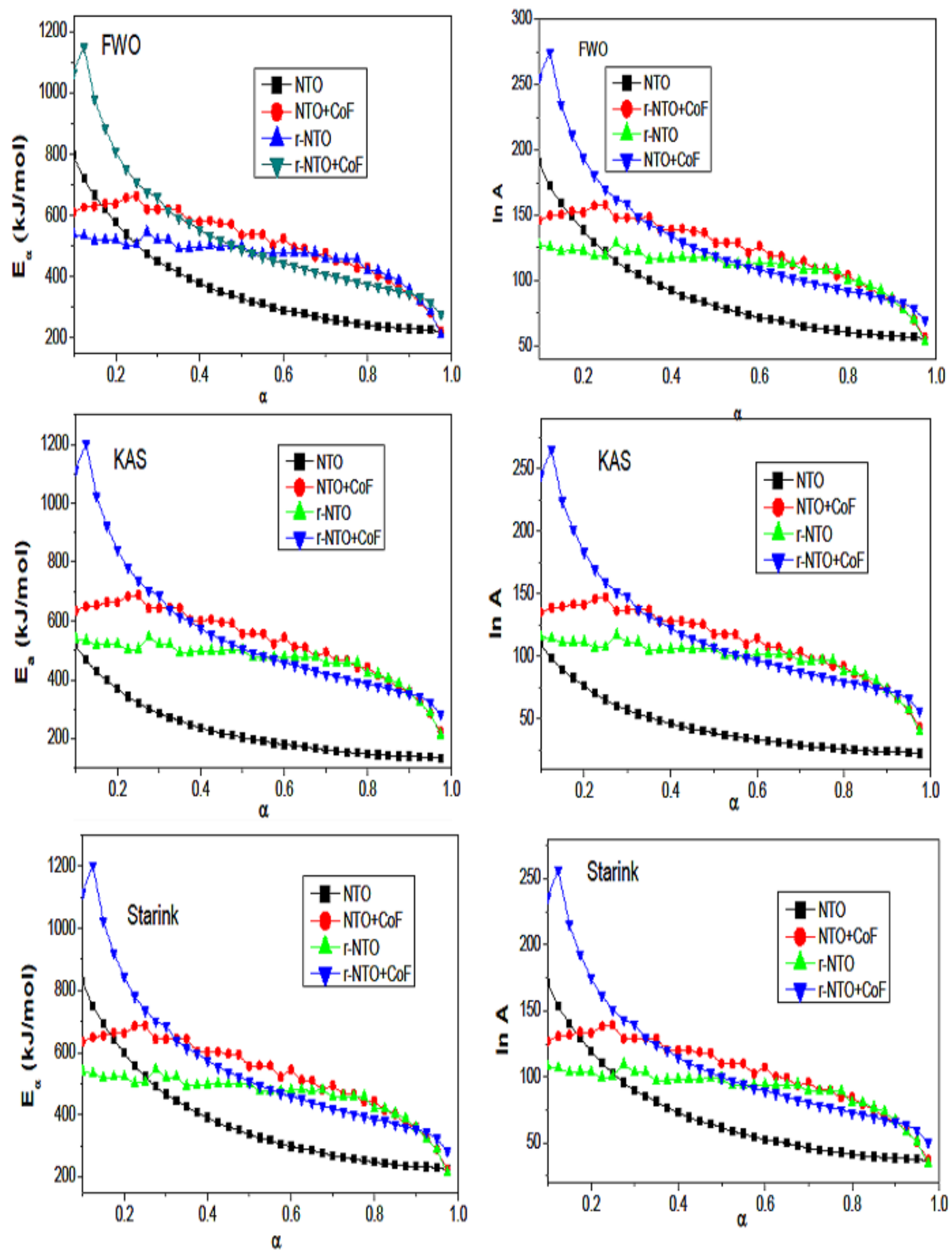

Figure 12

Variation in activation energy and pre-exponential factor at various extents of conversion calculated by FWO, KAS, and Starink method 
This is a list of supplementary files associated with this preprint. Click to download.

- GA.png

- SupportingInformation.docx 